\title{
Democracias cuestionadas. Elecciones competitivas, política de enemistad y desconfianza ciudadana ${ }^{1}$
}

\section{Questioned democracies. Competitive elections, politics of enmity and citizen mistrust}

Hugo Quiroga ${ }^{2}$

\section{Resumen}

Vivimos en una era de volatilidad que genera procesos disruptivos en las formas democráticas y en los sistemas políticos. Un tiempo marcado por el desconcierto y la perturbación. La inesperada crisis global del COVID-19 ha trastocado nuestras vidas y sociedades, extendiendo nuestro presente incierto y acelerando aún más el temor al futuro. La pandemia hizo más visibles las disfunciones del orden político liberal. Esas disfunciones remiten a la crisis del sistema de partidos, a la disolución de las identidades políticas masivas, a la fluctuación del voto, a los liderazgos de nuevo tipo - de manera frecuente con rasgos decisionistas o autoritarios-, a las desigualdades persistentes y múltiples, componentes que revelan una fatiga democrática, con degradaciones institucionales. En definitiva, asistimos a una generalizada deriva antiliberal, fundamentalmente política, especialmente en Europa y en los Estados Unidos de Donald Trump.

Palabras clave: democracia; sistema político; elecciones; desconfianza; ciudadanía

\begin{abstract}
We are living in an era of volatility that generates disruptive processes in the democratic forms and political systems. This time is marked by bewilderment and disturbance. The unexpected global crises due to COVID-19 has disrupted our lives and societies, extending this uncertain present and accelerating even more the fear to the future. This pandemic has made the public liberal political order malfunctions more visible. These malfunctions refer to the crisis of the parties systems, the dissolution of the massive political identities, the fluctuation of the vote, the new types of leaderships -frequently with some decisionist and authoritative features- and the multiple and persistent inequalities. These components reveal a democratic fatigue with institutional degradations. Ultimately, we assist to an antiliberal generalized uncertainty, fundamentally in politics, mainly in Europe and in the Donald Trump's US.
\end{abstract}

Keywords: democracy; political system; elections; mistrust; citizenship

1 Trabajo recibido el 28/03/2021. Aceptado el 09/06/2021.

${ }^{2}$ Universidad Nacional del Litoral. Consejo de Investigaciones de la Universidad Nacional de Rosario. Contacto: haquiroga@fibertel.com.ar 


\section{La deriva antiliberal}

Este texto se sitúa navegando en un mar de disrupciones políticas, las que representan un cambio determinante al introducir nuevos aspectos en las urgencias y emergencias de nuestras vidas colectivas. Ello no implica reemplazar de manera completa, ni definitiva, todo lo existente. Son situaciones, hechos, acontecimientos que irrumpen en el universo político y social, no necesariamente de manera brusca o súbita, que obligan a explorar nuevas respuestas diferentes a las tradicionales. Las disrupciones políticas nos fuerzan a indagar sobre diferentes conceptos, ignorados caminos y salidas desconocidas. No se puede dejar de reconocer que, desde cierto punto vista, estas innovaciones son más rápidas que nunca.

Vivimos en una era de volatilidad que genera procesos disruptivos en las formas democráticas y en los sistemas políticos. Un tiempo marcado por el desconcierto y la perturbación. El ascenso del populismo (de izquierda o derecha), los avances de la derecha antisistema, la xenofobia, el resurgimiento del nacionalismo extremo, aparecen justamente en los déficits de la democracia liberal. A medida que ésta decepciona, crece el antiliberalismo. ${ }^{3}$

Un conglomerado de derecha e izquierda congrega al iliberalismo político y económico y forma parte de una larga tradición de pensamiento que existe como fuerza política y como clima cultural. Es un conjunto de fenómenos que se engloban en la filosofía del iliberalismo. Los críticos de la doctrina y la acción liberal se agrupan hoy en diferentes familias políticas: la izquierda antisistema, el populismo y la extrema derecha.

Es sabido que el término «liberal», como sustantivo, fue forjado definitivamente en las Cortes Constituyentes de Cádiz en el año 1812, aunque su conceptualización fuera muy anterior. La posición del liberalismo político se construyó en el contexto de la Inglaterra del siglo XVII como antítesis del absolutismo, representado por sus primeros teóricos John Milton y John Locke. Por su parte, Adam Smith es considerado el padre del liberalismo económico con la producción de su obra La Riqueza de las Naciones, de 1776.

En el siglo XXI, la inesperada crisis global del COVID-19 ha trastocado nuestras vidas y sociedades, extendiendo nuestro presente incier-

\footnotetext{
${ }^{3}$ Remito al debate teórico sobre las raíces filosóficas e históricas del antiliberalismo en Holmes (1999).
} 
to y acelerando aún más el temor al futuro. La pandemia hizo más visibles las disfunciones del orden político liberal. Esas disfunciones remiten a la crisis del sistema de partidos, a la disolución de las identidades políticas masivas, a la fluctuación del voto, a los liderazgos de nuevo tipo -de manera frecuente con rasgos decisionistas o autoritarios-, a las desigualdades persistentes y múltiples, componentes que revelan una fatiga democrática, con degradaciones institucionales. En definitiva, asistimos a una generalizada deriva antiliberal, fundamentalmente política, especialmente en Europa y en los Estados Unidos de Donald Trump.

La democracia electiva ha sido sentada en el banquillo de los acusados desde hace, al menos, dos décadas. ¿Asistimos a un cambio de época? Los cambios del presente nos obligan a volver comprensible el movimiento de la historia, a interpretar el rumbo de la sociedad, a conocer las modulaciones de la conciencia de una época. La revolución tecnológica en la que vivimos modifica el régimen de interrogantes. Ellos giran en torno a lo social, a las desigualdades, al cambio de los actores políticos y a la revolución comunicacional. El léxico político que nos ayudó a explicar las sociedades industriales de la segunda mitad del siglo XX (los partidos políticos, el Estado-nación, las clases sociales) se enfrenta con las experiencias colectivas de una nueva época, con la necesidad de elaborar nuevas grillas conceptuales. Estas grillas nos tienen que ayudar a comprender la concreta realidad en la que vivimos, la vida común (Duso, 2009) y, al mismo tiempo, a reforzar una conciencia crítica de los conceptos que usamos en nuestro presente.

Este cambio de época expresaría, además, una «fatiga de la democracia», fracasos económicos, cansancio moral de los ciudadanos, decepciones colectivas, fracturas sociales, fragmentación política, temor al futuro. Este clima crea una profunda incertidumbre. El soberano no se siente representado. "Que se vayan todos», los políticos no nos representan, fue la consigna coreada en la crisis argentina de 2001-2002. El nudo central de un concepto tan litigioso como el de representación radica en la esperanza del reconocimiento de derechos, en los reclamos de los representados a sus representantes. Esto es, los representados no se sienten reconocidos por los representantes. Como se ha dicho, la edad de oro de los partidos ha finalizado.

Al retroceder en el tiempo, el vocablo pueblo y la idea de soberanía popular (fuente ilusoria del poder) poseen un largo y sinuoso recorrido. Son conceptos sin los cuales no podemos entender la democracia representativa. En verdad, el pueblo es un soberano colectivo, en el inte- 
rior de una sociedad fundada en la autonomía del individuo, de ahí su ambigüedad o indeterminación. En la modernidad política, el concepto «pueblo» irrumpe en el escenario europeo después de la revolución inglesa de 1688. El nuevo cuerpo político se asocia con la idea de «soberanía»-soberanía del pueblo- para seducir a las masas en la lucha de los que se oponen a las monarquías absolutas. Fue lo que aconteció abiertamente con la independencia americana de 1776 y con la Revolución Francesa de 1789. En definitiva, el término pueblo aparece coaligado con la idea de representación y democracia. La literatura sobre el tema puso de relieve que con la revolución de 1789 no sólo se luchaba contra la opresión de un orden jerárquico, sino también contra la explotación y la pobreza.

La noción de pueblo, única e indistinta, evoca a todos aquellos electores que no pueden estar presentes, que son invisibles en el espacio público gubernamental. Por eso, se habla de delegación de poder o poder delegado. «No hay lugar capaz de albergar a todos», y esto sólo es posible bajo la forma de representación, alega Arendt citando a John Selden, quien explica así la causa principal de la aparición del parlamentarismo (Arent, 1967). La democracia representativa es una democracia electiva, porque solo a través del sufragio universal se puede encauzar un gobierno representativo. La idea de igualdad política, «un hombre un voto», es moderna, como bien lo ha explicado Pierre Rosanvallon (1992). La naturaleza del sufragio universal, el carácter del cuerpo electoral y el derecho de voto fueron objeto de profundos debates en la Asamblea Constituyente francesa, debates que hoy aparecen bajo nuevos interrogantes.

Así comienza la travesía del asiento popular del poder desde el siglo XVIII hasta el presente. Esa travesía estuvo iluminada por teóricos y pensadores políticos desde el momento en que se instituyó la democracia representativa hasta llegar a una «democracia digital» del siglo XXI, habiendo atravesado la democracia de partidos. Con todo, en el siglo XIX el fundamento de la democracia para los autores de la época era la opinión pública. Pero, ¿qué es la opinión pública?, ¿̇el pueblo?, ¿los ciudadanos? En la actualidad, también se habla del «gobierno de opinión pública». ¿La «voluntad general» de Rousseau es equivalente a la «opinión pública» tal como hoy la denominamos?

En la actualidad, hay muchas voces que se levantan contra la democracia electiva. A la democracia representativa, ¿podemos seguir llamándola democracia?, ¿Cómo puede el pueblo ser soberano y súbdito, a 
la vez?, ¿para qué sirven las elecciones? He ahí, algunas de las preguntas de aquellos que visualizan un declive en la democracia electiva.

Estas son las cuestiones y preguntas que vertebran y ordenan mi artículo, que no deja de tener como horizonte de referencia algunos acontecimientos de la Argentina, y lo que sucede en el mundo. No se trata más que de argumentos abiertos. En estos años se ha producido transformaciones que hacen a la organización de nuestra vida colectiva; lo que pretendo es identificarlas en sus grandes tendencias -a través de conceptos y de la experiencia histórica- ya que su análisis ofrece pistas que pueden resultar comunes a numerosos países. Necesitamos una profunda crítica del presente, para imaginar el mañana, pero sin dejar de tomar en cuenta las lecciones del pasado.

\section{Principio electivo y elecciones competitivas}

La asamblea constituyente y la Constitución de 1791 de Francia concibieron a la elección como un acto de nombramiento de los representantes, que separó rigurosamente el derecho de elegir del derecho de deliberar y decidir. ${ }^{4}$ El objetivo de esa separación era mantener apartados a los ciudadanos de la voluntad política soberana. Los mandatarios no estaban encadenados a su mandato, por el contrario, ejercían una función libre, en cuanto ellos eran representantes de la nación y no de los ciudadanos considerados individualmente. La elección es un acto de confianza entre electores y elegidos, y no implica un mandato imperativo. No hay aquí misterios. En un régimen representativo los ciudadanos sólo son electores, en cambio en una democracia directa son legisladores.

De los debates fundadores del gobierno representativo, se desprende que la elección no supone una transferencia de poder de los ciudadanos, sino un modo de designación de aquellos que lo van a ejercer, puesto que los electores no han adquirido más competencia que la de elegir. El poder de los ciudadanos sobre sus representantes no es más que un poder de nombramiento, según ciertas interpretaciones del derecho público de Francia y Alemania de los siglos XVIII y XIX, que nos transmite Carré de Marberg, y que por tanto no puede interpretarse como una delegación de poder. Si bien la actividad electoral tiene un

\footnotetext{
${ }^{4}$ Remito a la monumental obra de Carré de Malberg (1998).
} 
carácter colectivo, en cuanto a su ejercicio, el cuerpo electoral no constituye un ser colectivo, no es una asamblea de ciudadanos que permanece después de la votación.

Aunque el ejercicio electoral es colectivo, los ciudadanos poseen un derecho individual (un derecho subjetivo de nombramiento) y, al mismo tiempo, cumplen una función pública por los efectos que produce ese ejercicio. El Estado se hace cargo del resultado electoral y le atribuye al cuerpo político el poder establecido en la Constitución y las leyes. Por tanto, el poder de las autoridades públicas no procede de los ciudadanoselectores sino de las leyes del Estado. En otras palabras, los ciudadanos sólo participan en el gobierno en el marco del derecho electoral y tienen una «pretensión subjetiva» de concurrir personalmente al nombramiento de los representantes. El sufragio universal, calificado como un derecho igual para todos, lo es únicamente en lo que concierne a la aptitud del voto y no en cuanto a sus efectos, porque puede resultar negativo para aquellos electores que constituyen la minoría.

A pesar de la naturaleza del gobierno representativo, los ciudadanos detentan un poder electoral, no en el sentido de un mandante sobre su mandatario como lo entiende el derecho privado, sino como un medio de ejercer influencia sobre las orientaciones generales de la política que habrán de implementar los gobernantes. El veredicto de las urnas siempre está presente y los representantes que deseen ser reelegidos deberán contemplar en su actuación las opiniones de los ciudadanos; hoy ese veredicto se ha extendido como nunca.

Al examinar la situación de la Argentina de fines del Siglo XX, las elecciones del 30 de octubre de 1983 fueron fundacionales, porque abrieron paso a la construcción de un orden democrático. Atrás quedaba un régimen autoritario que conmocionó a la sociedad hasta el límite de su dignidad, personificado en las fuerzas armadas. Fue necesaria la irrupción democrática, a partir de la actividad electoral, para que se pusiera en marcha un espacio público en el que la política concretaba su efectividad, y se basaba en la defensa de los derechos humanos. Fueron fundacionales también por la participación masiva de los ciudadanos, porque se clausuró el poder militar a través del juzgamiento a las Juntas Militares, y por la violación a los derechos humanos, que fueron acreditados en el Informe «Nunca Más», que elaboró la Comisión Nacional sobre la Desaparición de Personas (CONADEP). Hubo un voto antidictatorial y, por ende, un reclamo democrático, que rechazó aquellas formas de autoritarismo conocidas en la Argentina. 
Las acciones colectivas que sacudieron a la Argentina con posterioridad al colapso institucional de diciembre de 2001 fueron el símbolo más elevado del malestar con la representación. Fue tan alto el malestar de los ciudadanos que se tradujo en ira popular. Recordemos que en el año 2002 los dirigentes políticos no podían circular libremente por las calles ni asistir a lugares públicos sin temor a ser agredidos o repudiados, el Congreso de la Nación permaneció vallado durante un buen tiempo. La reacción de la ciudadanía golpeando cacerolas, la convocatoria de las asambleas vecinales y la protesta de los piqueteros fue una visible demostración del derrumbe del sistema de representación La consigna «Que se vayan todos», coreada masivamente en las calles, fue el símbolo de la indignación y la negativa a entablar una conversación, que se consideraba ya agotada, con los dirigentes tradicionales.

Esta tremenda crisis política fue resuelta finalmente por la presencia de los ciudadanos en las urnas. Así como hubo un voto antidictatorial en 1983 que puso fin al orden autoritario, hubo también un acto electoral sustancial para la vida democrática del país, por sus consecuencias políticas, veinte años después. En un momento decisivo de la Argentina contemporánea, los comicios de 2003 pusieron de manifiesto que la competencia electoral puede ser un medio eficaz de resolución de una crisis aguda, más allá de constituir un método de selección del cuerpo político.

De este modo, la política fue arrancada del peligro que significaba su deslegitimación. Un primer paso en esa dirección fue dado con la rutina electoral, aunque ello parezca casi imposible, luego siguieron otros que permitieron una mejor vecindad entre sociedad y política. El juego electoral, la selección de los gobernantes por los gobernados, es el gran principio de legitimidad democrática, y la elección, como advierte Raymond Aron (1999), es la organización más simple de la competencia pacífica con miras al ejercicio del poder, bajo ciertas reglas. La lucha electoral implica, al menos, la igualdad política, el derecho de todos los ciudadanos a participar en la competición. En la Argentina, la competencia electoral de 2003 fue la institución que permitió encauzar los efectos de la crisis de 2001.

Bajo ese clima de incertidumbre e inestabilidad algunos analistas plantearon que las elecciones formaban parte de la crisis antes que de la solución. Sin embargo, la salida electoral de 2003 resultó una opción adecuada ${ }^{5}$ para encauzar una complicada situación que guardaba hondas

${ }^{5}$ Una posición similar es sostenida por Isidoro Cheresky (2006). 
contrariedades en el campo político y económico, cuyos efectos devastadores amenazaban con la cohesión social. Tal salida, que implicaba continuar con el camino de la democracia y sus consultas rutinarias, permitió aglutinar a una sociedad que deseaba superar una realidad que hacía temblar la propia estabilidad del Estado. Tal vez fue el signo de maduración política de una sociedad que anhelaba tranquilidad y estabilidad, y escapaba del vacío y de la ausencia de otra alternativa.

Ahí, como nunca, democracia y elecciones confluyeron en una idea unitaria, la democracia electiva: la creación de una voluntad política pública como respuesta a la crisis. En esa especial circunstancia histórica, la relación de la ciudadanía con la política pasó principalmente por el voto. Hubo en esas circunstancias una toma de conciencia en el comportamiento ciudadano que reveló el cuidado que puso en la atención de la cosa pública. Entre las grandes instituciones de poder de la sociedad emerge en algún momento, con mucha más contundencia, el poder electoral.

Decíamos que las elecciones significan un acto de confianza entre representantes y representados, Por eso, en la «era de la desconfianza en la política», como sugiere Pierre Rosanvallon (2007), resulta paradójico que las elecciones de 2003 haya sido el medio que permitió encaminar la crisis. Si bien el espacio político no se reduce a las urnas, el sufragio se ha transformado en la Argentina en el dispositivo que representa (aun simbólicamente) la participación más orgánica e institucionalizada de los ciudadanos, más allá de los caminos no convencionales de la política: las protestas en la calle y las organizaciones sociales de carácter informal.

Las elecciones tienen un carácter simbólico y no representan un mero acto de nombramiento de gobernantes. La ficción de la soberanía popular se materializa en las elecciones. El símbolo, según Cassirer (1977), es parte del mundo humano del significado, los símbolos tienen un valor funcional. El poder electoral produce efectos en el universo de representación de los ciudadanos. Desde otra óptica, Dominique Schnapper (2003) señala que el voto democrático no sólo tiene por función regular la relación entre la sociedad y el poder, sino que es el símbolo de la sociedad política misma que asegura los lazos sociales y traza el destino de la colectividad.

El problema es que, en nuestro tiempo, el modelo representativo ha mutado y parece haber ingresado en una fase de agotamiento que, para muchos, desvirtúa la idea misma de la democracia moderna. Más allá de los válidos cuestionamientos a esos principios tradicionales, la 
democracia contemporánea no se ha convertido tampoco en una expresión de combates argumentativos, no es la condensación de opiniones contrapuestas. Sí es un lugar de conflictos diversos, políticos, económicos, sociales, culturales construyen la argumentación pública y la decisión política.

No obstante, la democracia también constituye la única forma de gobierno que descansa en el consentimiento del pueblo, el cual tiene múltiples formas expresión, no sólo la electoral. La arena política ya no se reduce al parlamento, se ha ampliado debido a la presencia de nuevas formas de representación -como, por ejemplo, los movimientos informales- e, igualmente, por las variables formas de legitimidad virtual.

Legitimidad y representación confluyen, entonces, en la conformación de una voluntad política pública, que es concebida como una fuerza institucionalizada y aceptada en derecho. Esa voluntad es el resultado de una competencia electoral pluralista, transparente, con reglas claras, sin proscripciones, en la que se ofrecen candidaturas a través de partidos, frentes o coaliciones para que los electores escojan. La voluntad política pública se debe a un proceso compartido entre el ejecutivo y el legislativo, en tanto el parlamento es un órgano de codecisión. En la práctica institucional de los regímenes democráticos, en términos generales, la codecisión no funciona como tal.

En definitiva, ¿́cuándo es competitiva una elección? Cuando no hay manipulación estatal ni clientelismo. Se tienen en cuenta, en ese caso, una serie de reglas que no pueden ser agotadas por criterios técnicos y externos. El umbral de libertad o de regularidad de una elección no se decreta; depende del estado anterior de las instituciones y de lo que esperan los ciudadanos. La cultura política es el resumen de una historia que se manifiesta mediante un conjunto de valores, de actitudes y expectativas

\section{La competencia política a través de elecciones y sorteo}

Votar no es un hecho irrelevante en el sistema democrático. Pero no se trata únicamente de votar, sino de organizar mejor el espacio público y el poder democrático, que es un poder esparcido en la sociedad. Los dirigentes y los ciudadanos tienen la obligación de preservar ese capital político acumulado por el esfuerzo de una sociedad entera que 
hizo una apuesta por una convivencia pacífica, libre, solidaria y razonable.

En mi opinión, lo que «inventa» la democracia moderna es la comunidad electoral, fundada en la igualdad política de los individuos, en los principios de igualdad y libertad, que la aleja de la comunidad orgánica de la antigüedad, instituida en los principios de jerarquía y tradición. Aún de manera elemental, esa comunidad electoral implica una pertenencia colectiva, que va más allá de las preferencias individuales por los candidatos o partidos. A través de la comunidad electoral el cuerpo social se convierte en cuerpo político. No obstante, hay que reconocer que una comunidad electoral no configura una verdadera comunidad política, con un sentido más amplio que el de los derechos políticos. La duda que salta es si la democracia representativa no se ha reducido a un sistema de votación. Lo que se ha reafirmado es la democracia electoral.

Es cierto, la actividad electoral tiene un carácter colectivo en cuanto a su ejercicio -el hecho de votar-, aunque el cuerpo electoral no constituya un ser colectivo (no todos los ciudadanos felizmente piensan igual); no es una asamblea de ciudadanos que permanece después de la votación, lo que no impide que haya controles post-electorales, pero no como sujeto colectivo. Con todas sus deficiencias, lo que legitima la democracia representativa es el principio electivo, la igualdad política (un hombre, un voto) y las elecciones competitivas, y no un «yo» colectivo, abstracto, que ejerce un poder soberano unívoco, indivisible, sobre los mandatarios. De su propia experiencia como diputado de la Asamblea de 1848 escribía Proudhon en 1870: «Siempre, a pesar de los principios, el delegado del soberano será el dueño del soberano». ${ }^{6}$ Así las cosas, que ya fueron dichas, estamos delante de una paradoja insalvable: la soberanía delegada. La soberanía popular es subrogada por el cuerpo político. La búsqueda de respuesta a estos interrogantes exige nuevas categorías de análisis. Necesitamos nuevas grillas interpretativas para poder dar cuenta de los complejos problemas planteados por las relaciones de poder en sociedades mediáticas.

La legitimidad democrática se configura, en nuestra visión, a través de la sucesión pacífica del poder, en la competencia política, con elecciones limpias, plurales, y competitivas. A pesar de lo que numerosos autores ponderan con insistencia, la democracia moderna, como comunidad electoral, se define mejor por la idea de elecciones competitivas

${ }^{6}$ Citado en De Jouvenel (1998, p. 176). 
antes que por el sufragio universal propiamente dicho. Lo que distingue a la democracia contemporánea no es tanto el sufragio universal como la elección competitiva, el ejemplo paradigmático fue el PRI (Partido Revolucionario Institucional) en México que gobernó durante setenta años, sin alternancia política. Es lo que nos enseñó Giovanni Sartori, en su clásica obra Partidos y sistemas de partidos. 1, sobre los sistemas no competitivos, aunque no haya proscripciones políticas.

En efecto, hay numerosos ejemplos de ejercicio del derecho de voto, pero al no funcionar una competencia abierta y pluralista por el poder, las elecciones pierden el sentido elemental de competitividad. El sistema político argentino mantuvo durante décadas características muy singulares, en lo que se refiere al principio de legitimidad, que define al régimen democrático. Por un lado, carecieron de legitimidad de origen los gobiernos de Arturo Frondizi (1958-1962) y Arturo Illia (1963-1966), cuando ambos regímenes nacieron de la proscripción del partido peronista, notoriamente mayoritario en su época. El sufragio universal funcionó sin «inconvenientes», pero las elecciones no fueron competitivas. ${ }^{7}$

Por el otro, durante el gobierno peronista de 1973-1976, que triunfó con el $62 \%$ de los sufragios, la legitimidad de origen fue opacada por la ausencia de la legitimidad de ejercicio. No se trata solamente de las deficientes políticas públicas (el «Rodrigazo» de 1975), sino de un grave hecho institucional que altera la legitimidad de la democracia. Se alude a la creación, desde el Ministerio de Bienestar Social del Estado nacional, de una fuerza parapolicial denominada Tripe A (Alianza Anticomunista Argentina), responsable de atentados, asesinatos de políticos, sindicalistas, sacerdotes, artistas, intelectuales. Desde ese Ministerio, conducido por José López Rega, se organizó y financió esa organización terrorista. Un antecedente del terrorismo de Estado de 1976, pero esta vez puesto en práctica desde un estado democrático. Esas acciones fueron definidas como delitos de lesa humanidad por la justicia en primera instancia y confirmada por la Cámara Federal en el año 2008.

Como lo adelantamos, en la actualidad, se fortalece una vasta literatura que se interroga para qué sirven las elecciones, ya que ellas no agotan el significado de la palabra democracia, razón por la cual, sin que sean excluidas, hay que buscar otras formas de participación e intervención ciudadana. En este paisaje político sobrevuelan interrogantes que inquietan a los observadores: ¿qué votan los ciudadanos?, ¿votan pro-

${ }^{7}$ Remitimos a Cavarozzi (1997). 
gramas o votan líderes de popularidad construidos por los medios?, ¿̇o votan por otros motivos?, y ra quiénes votan?, sobre todo en un contexto de crisis y fragmentación de los partidos políticos.

Como ya se anticipó, las elecciones son un procedimiento para establecer la democracia, pero no son la democracia misma. Una ley electoral es un mecanismo de transformación del número en nombres (Pasquino, 2013). Se trata de una «regla de autorización», de un dispositivo de elección de gobernantes que hay que analizar por oposición a otros mecanismos del mismo tipo, entre ellos, los concursos públicos y el sorteo. Las elecciones son una forma de autorización «desde abajo» $\mathrm{y}$ constituyen una regla de asentimiento de los ciudadanos que carecen de poder para gobernar.

La competencia política se puede organizar a través de dos instituciones, las elecciones y el sorteo. En el mundo ateniense tuvo mayor relevancia el sorteo, mientras que con la modernidad política emerge el principio electivo. Hoy, se reivindica al sorteo como una institución verdaderamente democrática. El debate queda abierto. ¿́puede la elección ser presentada siempre como el fundamento de la democracia? Para ciertos autores, desde una posición más radical, los términos «elección» $\mathrm{y}$ «democracia» se han convertido en sinónimos en casi todo el mundo; y en este sentido afirman que quien dice democracia dice elecciones. Sostienen, asimismo, que nos hemos convertido en «fundamentalistas de las elecciones» (Van Reybrouck, 2013, p. 52). En ese contexto, se desprecia a los representantes, pero se veneran las elecciones.

Desde esta perspectiva, el sorteo es una formidable escuela de formación democrática, y un dispositivo de rotación que determina el carácter democrático del gobierno. De este modo se evita la profesionalización de las carreras políticas mediante un aprendizaje de los asuntos públicos abierto a todos (Hermet, 2009). Entre otros autores, Manin recuerda que la elección implica una actitud elitista, ya que lo implícito es que ciertos individuos pueden ser considerados más aptos que otros para gobernar. Por eso, el sorteo es descrito como el modo de selección democrático por excelencia, mientras que la elección aparece más bien como oligárquica o aristocrática (Manin, 1995).

Ahora bien, en algunas democracias contemporáneas ${ }^{8}$-como por ejemplo, las de Islandia, Gran Bretaña, Estados Unidos, Alemania, la

${ }^{8}$ Sobre el particular, véase: Van Reybrouck (2013), Elster (2013), Sintomer (2007), Dupuis-Déri (2013). 
ciudad griega de Maroussi, el gobierno de British Columbia Canadá, los Países Bajos, Ontario, etc.- en oposición a las elecciones, el sorteo político alude a la toma de decisiones por parte de ciudadanos seleccionados aleatoriamente mediante el sorteo. ${ }^{9}$ Son funciones ciudadanas todavía limitadas, que van creciendo, en las democracias actuales.

No se trata de eliminar la elección, sino de institucionalizar el sorteo como un modo de enriquecer la democracia, ampliar las bases de la toma de decisiones, y marchar hacia una democracia más participativa. Sin ninguna incompatibilidad, la elección puede estar asociada al sorteo. En una época en la que sobresalen las redes sociales y se ha puesto fin a los partidos de masas, se multiplican las vías de legitimidad democrática y se ensancha la pluralidad de voces.

El propósito es incrementar la participación ciudadana factible y real. La experiencia más remarcable es la de Islandia. En 2009, con el propósito de iniciar un proceso de reforma de la Constitución, se creó una Asamblea Nacional compuesta por 1500 personas, de las cuales 1200 fueron seleccionadas aleatoriamente del registro civil, mientras que las 300 restantes fueron seleccionadas entre diversas asociaciones. En ese proceso las redes sociales jugaron un rol significativo. En 2004, por otra parte, el gobierno de la provincia canadiense de Columbia Británica había elaborado una reforma electoral a través de la creación de una Asamblea Ciudadana, cuyos miembros también fueron seleccionados de manera aleatoria. Las recomendaciones de la Asamblea fueron sometidas al veredicto público de un referendo (Sintomer, 2011).

En el sistema político argentino no se ha instituido el mecanismo del sorteo, ni siquiera en el ámbito judicial. A pesar de que la Constitución establece, en el artículo 24 -y sus concordancias: artículos 75 , inciso 12; y 118- la posibilidad de administrar justicia en materia penal en el orden nacional y provincial a través del juicio por jurado. En el orden nacional no se ha sancionado aún la ley que la regule. Ello dio lugar a una interpretación sobre la situación de inconstitucionalidad por omisión legislativa (Gelli, 2011). En efecto, los constituyentes de 1853 se inspiraron en el modelo de Estados Unidos, que funda la legitimidad de las instituciones de la república en la soberanía del pueblo.

El juicio por jurado significa que un grupo de ciudadanos sin formación jurídica determina la culpabilidad o inocencia del acusado a partir de emitir un dictamen sobre los hechos, pero no juzga sobre el dere-

\footnotetext{
${ }^{9}$ Para el caso de América Latina, se puede consultar Roth Deubel (2013).
} 
cho que se debe aplicar. En cambio, hay cinco provincias argentinas Buenos Aires, Córdoba, Neuquén, Chaco y Río Negro, que mediante leyes provinciales han regulado por el juicio por jurados populares. La más avanzada es la provincia de Buenos Aires que ha realizado sus primeros juicios en 2015. Los jurados solo se pueden constituir por delitos graves, que son aquellos que pueden tener condenas de más de 15 años. El jurado está compuesto 12 miembros, por paridad de género; en 2017, hubo un veredicto de prisión perpetua por femicidio.

\section{El concepto móvil de democracia}

¿Crisis o mutación de la democracia? ¿Ocaso o reinvención de la representación? Desde el momento en que la democracia representativa se debilita, los términos «posdemocracia» (Crouch, 2013) «democracia posrepresentativa», «desdemocratización» (Tilly, 2010) comienzan a ser pronunciados por numerosos autores en los últimos años. El prefijo «pos» nos indica algo: «después de». Preguntamos: ¿Hay un agotamiento de la democracia actual, tal como la conocemos? ¿La democracia debe ser reemplazada por un nuevo régimen político? ¿Cuál? Las respuestas pueden ser de la más variadas, y lo son. En todo caso la democracia representativa ha sido puesta a prueba, porque sus principios fundamentales no dan las repuestas satisfactorias para las que habían sido creadas. El mecanismo electoral le queda chico a la democracia representativa. La idea de sorteo político apunta a una ampliación del espacio público participativo De ahí que se hace un tanto difícil conocer el significado actual de la palabra democracia

Es difícil nombrarla hoy porque no existe «la» democracia, sino «las» democracias», quizá desde un punto de vista teórico haya coincidencias (por ejemplo, el voto), pero en la realidad hay una complejidad de variantes o versiones que al fluctuar ${ }^{10}$ la vuelven indefinible. Muchos gobernantes se autodefinen como democráticos, pero en los hechos son gobiernos autocráticos, que han sido elegidos por el sufragio universal. Entre otros casos, el parlamento húngaro le otorgó a Viktor Orbán poderes extraordinarios, sin límites temporales y sin control frente a la crisis sanitaria mundial. Estos fenómenos con sus diferentes variantes se

${ }^{10} \mathrm{Al}$ concepto de democracia fluctuante o móvil lo tomo prestado de Bordoni (2016, p. 178). Es un concepto que evoluciona junto con la sociedad. 
van extendiendo a otros lugares en detrimento de la libertad amparados por la emergencia de la pandemia.

El problema, a mi entender, es que todavía no aparece la alternativa a la democracia representativa; es por ello que se habla de post-democracia, democracia post-representativa, o desdemocratización. No se puede dejar, como dijimos, de reverenciar su nombre, aunque sea con el prefijo «post». Quizá la respuesta se encuentre en buscar un nuevo orden, y no en su renovación. En la actualidad, el riesgo de fondo es la débil estructuración de la democracia, su desvío hacia soluciones autoritarias, donde se pondría a prueba, nuevamente, la relación entre política y libertad, y cuyo resultado sería una sociedad libre o una despótica.

Entre fines del siglo XIX y principios del XX la democracia política liberal organizó de forma coherente la gestión pública del poder, en tanto la práctica representativa era progresivamente aceptada y ampliada por el sufragio universal, principalmente masculino. La democracia política, como sistema representativo, fue paulatinamente instalada. Con el paso del tiempo, las críticas a ese modelo aumentaron en intensidad por diversos motivos. Toda valoración que se realice de la democracia del siglo XX y del XXI estará condicionada por circunstancias espaciales y temporales, pues la construcción democrática hunde sus raíces en la experiencia histórica de cada nación.

Es sabido, la democracia es un proyecto inacabado e inacabable, es una sociedad que no se cierra nunca en sí misma. Su acta de nacimiento la encontramos en la antigua Grecia, y reaparece lentamente siglos más tarde hasta su consagración a partir de la revolución francesa. Ese viaje, complicado e incierto, hace escala en nuestros días como si la democracia fuera una institución mundial, ${ }^{11}$ que se contrapone a la economía globalizada. En este proceso emergen con más nitidez los malestares en la democracia representativa en la medida que surgen serios cuestionamientos a sus principios fundadores: la legitimidad y la representación. La desigualdad social y cultural, la brecha abismal entre ricos y pobres, son algunos de los rasgos peculiares de lo que todavía seguimos nombrando como democracia representativa.

Es cierto, como lo reconocen algunos autores, la democracia vive en permanente estado de tensión o en crisis. Con tono pesimista, en un libro publicado en inglés en 1933 (The Democracy in crisis), Harold Laski (1946) advertía -en el contexto de la convulsionada Europa de los años

${ }^{11}$ Para una historia de la democracia véase Canfora (2004). 
veinte y treinta- que los fundamentos de nuestra civilización estaban sometidos a una crítica profunda que no tenía precedentes desde los tiempos en que Rousseau lanzó sus condenas y fulminó al siglo XVII. Para Laski el estilo de vida occidental estaba descomponiéndose. En otras palabras, el carácter de la «democracia capitalista» afectaba a todos los aspectos de la civilización, de manera particular a las instituciones políticas del Estado moderno. La decadencia del sistema político se debió a su impotencia por incorporar un nuevo espíritu diferente al que contenía, espíritu que trae consigo su propio sentido de valores, y la búsqueda de un nuevo equilibrio entre orden y libertad.

Las implicancias del antiliberalismo son globales y atraviesan los dos continentes. La democracia liberal siente la embestida de los «enemigos internos y externos» (Todorov, 2012, p. 8) aunque en esa embestida se descubra que el enemigo interno es mucho más inquietante. Los cambios en el paisaje político se aceleraron después del final de la guerra fría. Hoy, pareciera que el orden de posguerra -el orden mundial liberal- con su modelo geopolítico de dominación de más de setenta años, está cuestionado por una ola de nacionalismos, xenofobia, por la primacía de los intereses nacionales (el proteccionismo está en alza) -el caso del Presidente Trump fue emblemático en Estados Unidos-, por el abandono de Gran Bretaña de la Unión Europea. Se trata de los dos arquitectos más relevantes en la creación de ese orden mundial. Esta conmoción se percibe reforzada por el papel más amenazante de Rusia y el creciente poderío de China, con un poder político cada vez más concentrado en manos de su líder, sumado al autoritarismo de Turquía. El resultado muestra el resurgir de la política de las grandes potencias, así como las esferas de rivalidad entre ellas. El clima político que impera en muchas de las democracias occidentales es el del antagonismo y no el de adversarios que compiten legítimamente por el poder democrático; se asemejan más a la rivalidad de amigos -enemigos que a la de amigos-adversarios.

La multiplicidad de las mutaciones en la democracia liberal, su ritmo vertiginoso, los avances de la tecnología de información y la comunicación, ha modificado el vínculo de los ciudadanos con el poder, con los partidos, con el régimen tradicional de poder, con la política. Las urnas conservan, sin embargo, su rol canalizador -material y simbólico- de la representación. Pero ahora lo comparten con Internet, con la Web, las redes sociales.

El concepto de representación revela una paradoja ineludible. La representación es un principio fundador de la democracia y es, a la vez, 
su punto débil. Los ciudadanos conceden y legitiman el poder de los representantes y éstos se autonomizan y toman distancia de los electores. Lo que se instituye es una distancia representativa. En tal sentido, todavía ignoramos el perfil que puede llegar a presentar la democracia del siglo XXI a la luz de estas mutaciones, entre las que se incluye una verdadera revolución comunicacional.

En las condiciones actual del juego político la desconfianza ciudadana se incrementa. Lo que cambia es el vínculo de los ciudadanos con el poder, con los partidos, con el régimen tradicional de representación, con la política. Ese desencanto con funcionarios, gobernantes y políticos da lugar a una ciudadanía frustrada, porque se la priva de lo prometido y esperó.

Asistimos a la era del gobierno de los ejecutivos. La concentración del poder es su rasgo principal. Se pretende subordinar al Congreso y al poder judicial, lo que erosiona cualquier forma de control de la democracia representativa. El riesgo son los abusos y arbitrariedades del poder concentrado. Bovero alerta sobre deriva de la democracia electiva hacia una «autocracia electiva» (Bovero, 2002, p. 168). Los ejemplos comienzan a extenderse. En mi interpretación he propuesto la noción de «decisionismo democrático» (Quiroga, 2005). Se trata, esencialmente, de un gobierno del ejecutivo que le incorpora poderes incontrolados al presidente, tanto en épocas de emergencia como de normalidad. Cuando se ensancha la esfera del ejecutivo, se desplaza el debate público, y como resultante de ello, el parlamento pierde poder y capacidad de control.

Un orden político legítimo, pacífico y justo, basados no solo en principios electivos, sino también en el sorteo político, es nuestro presente y en nuestro porvenir. Una manera de mejorar la democracia representativa es la posibilidad de asociar la elección al sorteo como un modo de revitalizar la acción ciudadana. Pensar el presente y sus transformaciones es la tarea que tenemos por delante de manera colectiva. El cuidado de la democracia depende de los gobernantes y de la ciudadanía.

\section{Referencias bibliográficas}

Arendt, H. (1967). Sobre la revolución. Madrid, España: Ediciones de la Revista de Occidente. 
Bauman, Z. y Bordoni, C. (2016). Estado de crisis. Buenos Aires, Argentina: Paidós.

Bovero, M. (2002). Una gramática de la democracia. Contra el gobierno de los peores. Madrid: Trotta.

Bordoni, C. (2016). En. Bauman, Z. y Bordoni, C. Estado de crisis. Buenos Aires, Argentina: Paidós.

Canfora, L. (2004). La democracia. Historia de una ideología. Barcelona, España: Crítica.

Carré de Malberg, R. (1998). Teoría general del Estado. México, México: Fondo de Cultura Económica.

Cassirer, E. (1977). Ensaio sobre o Homen. Introduçào a una filosofia da cultura buamana. Sào Paulo, Brasil: Martins Fontes.

Cavarozzi, M. (1997). Autoritarismo y democracia (1995-1996). Buenos Aires, Argentina: Ariel.

Cheresky, I. (Comp.). (2006). Ciudadania, sociedad civil y participación política. Buenos Aires, Argentina: Miño y Dávila.

Crouch, C. (2013). Post-démocratie. París, Francia: Diaphanes.

De Jouvenel, B. (1998). Sobre el poder. Historia natural de su crecimiento. Madrid, España: Unión.

Dupuis-Déri, F. (2013). Démocratie. Histoire politique d'un mot. Aux ÉtatsUnis et en France. Quebec, Canadá: Lux.

Duso, G. (2009). Pensar la política más allá de los conceptos modernos: historia de los conceptos y filosofía política. En Chignola, S. y Duso, G., Historia de los conceptos y filosofía politica. Madrid, España: Biblioteca Nueva.

Gelli, M. A. (2011). Constitución de la Nación Argentina. Comentada y concordada. 4ta edición Ampliada y actualizada, Tomo I. Buenos Aires, Argentina: La Ley.

Hermet, G. (2009). El invierno de la democracia. Auge y decadencia del gobierno del pueblo. Barcelona: Los libros del lince.

Holmes, S. (1999). Anatomía del Antiliberalismo. Madrid, España: Alian$\mathrm{za}$.

Laski, H. (1946). Crisis de la democracia. Buenos Aires, Argentina: Siglo veinte.

Elster, J. y Le Pillouer, A. (Dirs.) (2013). Á quoi servent les élections. París, Francia: PUF. 
Manin, B. (1995). Principes de gouvernement represéntatif. París, Francia : Calmann_Lévy.

Pasquino, P. (2013). Nature e limites du principe de majorité. En Elster, J. y Le Pillouer, A. (Dirs.). Á quoi servent les élections. París, Francia: PUF.

Quiroga, H. (2005). La Argentina en emergencia permanente. Buenos Aires, Argentina: Edhasa.

Quiroga, H. (2010). La democracia que no es. Politica y sociedad en la Argentina (1983-2016). Buenos Aires, Argentina: Edhasa.

Raymond, A. (1999). Introducción a la filosofía politica. Democracia y revolución. Barcelona, España: Piados.

Reybrouck, D. (2013). Contre les élections. Bélgica: Babel.

Rosanvallon, P. (2007). La Contrademocracia. La politica en la era de la desconfianza. Buenos Aires, Argentina: Manantial.

Rosanvallon, P. (1992). Le sacre du citoyen. Histoire du suffrage universal en France. París, Francia: Gallimard.

Schnapper, D. (2003). La communauté des citoyens. Sur lidée moderne de nation. París, Francia: Gallimard.

Sintomer, Y. (2007). Le pouvoir an peuple. Jurys Citoyens, tirage an sort $e$ démocratie Participative. París, Francia: La Découverte.

Sintomer, Y. (2011). Petite histoire de l'expérimentation démocratique. Tirage au sorte et politique de Athènes á nos jours. París, Francia: La Découverte.

Holmes, S. (1999). Anatomía del Antiliberalismo. Madrid, España: Alianza.

Tilly, C. (2010). Democracia. Madrid, España: Akal.

Todorov, T. (2012). Les ennemis intimes de la démocratie. París: Francia: Robert Laffont.

Van Reybrouck, D. (2013). Contre les élections. Bélgica: Babel.

Roth Deubel, A-N. (2013). Democracia participativa en América Latina: el uso del sorteo como dispositivo democrático para una gobernanza post-estatal. Revista del CLAD Reforma y Democracia, 56. 